\title{
Present-day testing of a paleoecological pattern : is there really a latitudinal difference in leaf-feeding insect-damage diversity?
}

\begin{abstract}
The fossil record suggests greater diversity of insect leaf feeding during warm climate intervals. Much published work in the paleobotanical literature has been based on the presumed validity of this pattern. However, the existence of this pattern in nature has never been tested from the present-day world. Here we ask, is it true that on average, in warmer climates, a leaf is being eaten in more ways? We compared forests at seven sites in northern Florida $\left(30^{\circ} \mathrm{N}\right.$, MAT ca. $\left.19.5^{\circ} \mathrm{C}\right)$ to seven sites across the north-eastern USA $\left(40-42^{\circ} \mathrm{N}\right.$, MAT 7-9 $\left.{ }^{\circ} \mathrm{C}\right)$. Presence and absence of damage types were determined using a standard leaf damage guide; 93 damage types were found in the Florida samples and 80 in the northeastern samples. In bulk floras, there was a consistent difference in damage diversity, on a per-leaf basis (as in the fossil studies), between Florida and north-eastern sites. Florida sites had a greater number of damage types. When northern and southern populations of individual tree species were compared, higher southern damage diversity was found in four species (Acer rubrum, Acer saccharum, Fagus grandifolia, and Quercus coccinea), though with no difference with latitude in a fifth species (Quercus alba). These results appear to validate that the trend seen in the fossil record is not a spurious effect of site differences. They also extend a pattern seen in deep time into the present day, adding greatly to its generality.
\end{abstract}

Keyword: Herbivory; Climate; Latitude 